\title{
Omental cysts in children: Rare causes of abdominal masses (a report of two cases)
}

\author{
Ibrahim E. Bassiouny, Tariq O. Abbas* \\ Pediatric Surgery Department, Hamad General Hospital, Doha, Qatar \\ Email: ibassiouny@yahoo.com, ${ }^{*}$ tariq2c@hotmail.com, *Tabbas@hmc.org.qa
}

Received 17 November 2013; revised 10 December 2013; accepted 18 December 2013

Copyright (C) 2013 Ibrahim E. Bassiouny, Tariq O. Abbas. This is an open access article distributed under the Creative Commons Attribution License, which permits unrestricted use, distribution, and reproduction in any medium, provided the original work is properly cited.

\begin{abstract}
Background: Omental cysts are the least common variety of intraabdominal cystic lesions encountered in children. They are often identified incidentally, although they may also cause acute abdominal pain. Case Report: We describe here two girls with omental cysts with very unusual clinical presentations. Conclusion: The majority of omental cysts are discovered incidentally. Overall results in pediatric patients are favourable. Optimal surgical management mandates complete excision.
\end{abstract}

Keywords: Omental Cyst; Pediatric; Teratomatous

\section{INTRODUCTION}

Omental cysts are extremely rare category of intraabdominal cystic lesions encountered in children. Pathologically, these lesions are generally single, although multiple occurrences have been reported. They may be unilocular or multilocular and contain fluid which may range from a clear, straw-colored liquid to a thick cheesy-white material which is thought to be inspissated lymph fluid. It is now recognized that there is no single etiologic mechanism involved in the development of all these cysts. The literature contains several examples of cysts which are definitely congenital, but there are also a large number of definitely acquired cysts which have been reported. It is obvious that a very small cyst may be asymptomatic and nonpalpable and therefore discovered only as an incidental finding at operation: 1) they are often identified incidentally, although they may also cause acute abdominal pain; 2) mesenteric cysts are indeed rare, and have been omitted from some surgical textbooks. However, the subject deserves more consideration because of the very fact that the cysts are fre-

*Corresponding author. quently overlooked. Consequently, inappropriate treatment and late diagnoses are common in the management of mesenteric cysts; 3) we describe here two girls with omental cysts with very unusual clinical presentations.

\section{CASES}

\subsection{Patient 1}

A 2-year-old girl presented with pallor and lethargy. She has a normal uneventful past medical history. Physical examination revealed a temperature of $36.8^{\circ} \mathrm{C}$, a pulse of $150 \mathrm{bpm}$, a respiratory rate of 24 per minute, and a blood pressure of 115/70 mmHg. Her abdomen was moderately distended, soft, and lax, with no tenderness. Blood workup showed a hemoglobin $(\mathrm{Hb})$ concentration of 5 $\mathrm{g} / \mathrm{dl}$, Ht 21\%, a white blood cell (WBC) count of $7.1 \times$ $10^{3} / \mathrm{ul}$, and a platelet count of $208 \times 10^{3} / \mathrm{ul}$. Her coagulation profile, renal and liver functions tests, and serum amylase were normal.

Ultrasound revealed massive ascites with fine septation, diagnostic of hemorrhagic ascites. She received a blood transfusion of $15 \mathrm{ml} / \mathrm{kg}$, which increased her $\mathrm{Hb}$ concentration to $12.1 \mathrm{~g} / \mathrm{dl}$. An abdominal CT scan showed massive ascites surrounding the liver and extending to the pelvis, with displacement of the bowel loops posteriorly. There was no evidence of injury to the solid organs or vascular structures (Figure 1).

Abdominal paracentesis was performed yielding hemorrhagic fluid with a red cell count of 2,320,000/ul; a WBC count of $2980 / \mathrm{mm}^{3}$, with $10 \%$ neutrophils, $85 \%$ lymphocytes, $1 \%$ monocytes, and $4 \%$ eosinophils; bacterial and fungal cultures and cytology were negative. Some degenerated mesothelial cells and macrophages were also observed.

After tapping, the patient developed abdominal pain. Her $\mathrm{Hb}$ dropped to $5.9 \mathrm{~g} / \mathrm{dl}$ after 4 days, and she needed a second blood transfusion.

Tc 99 sulfur colloid abdominal scintigraphy showed 


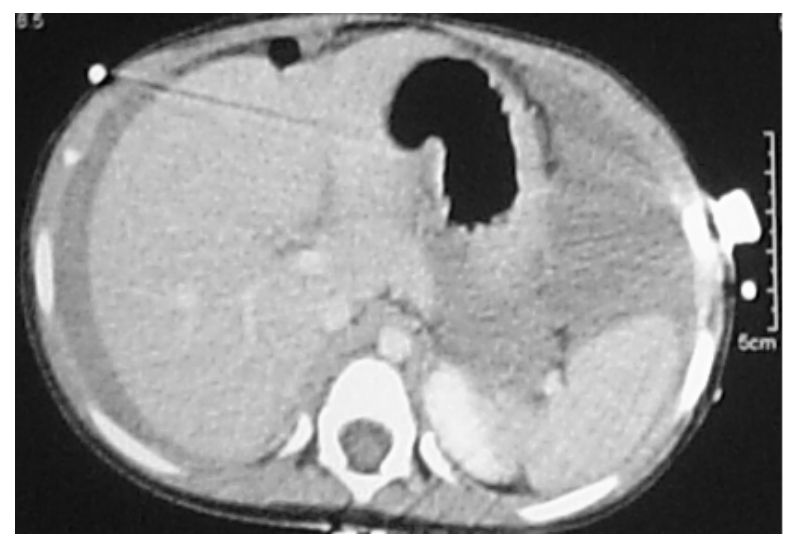

(a)

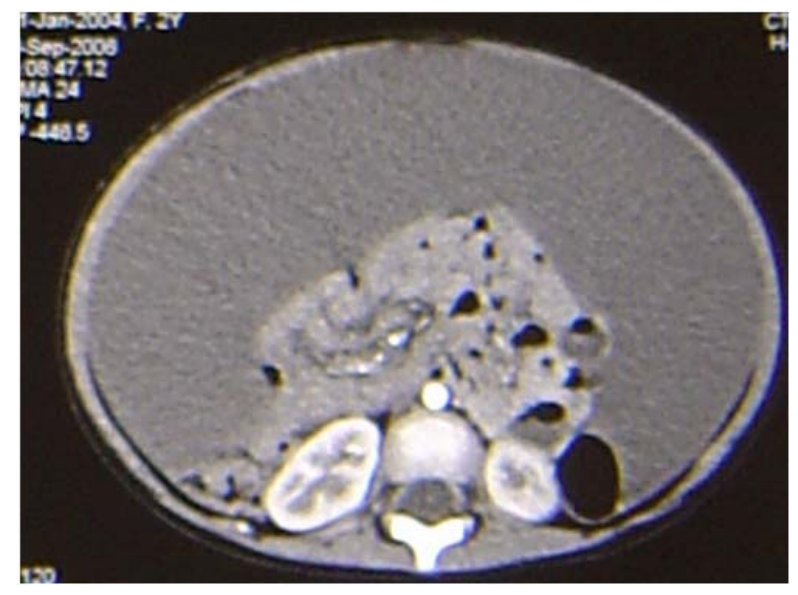

(b)

Figure 1. CT of the abdomen in patient 1. (a) shows massive hemorrhagic ascites, with the fluid dispersed around the liver and spleen, displacing the centrally located and clumped intestinal loops posteriorly; (b) There were no septa or loculation of the collected fluid.

no active point of bleeding inside the abdominal cavity. Throughout her stay in the hospital, she was fed orally. Ten days later, her $\mathrm{Hb}$ had dropped to $6.3 \mathrm{~g} / \mathrm{dl}$; a repeat CT yielded the same findings.

At laparotomy, no free blood was found in the peritoneal cavity. We observed a unilocular, huge thin-walled omental cyst about $15 \times 9 \mathrm{~cm}$ filled with blood-stained fluid arising from the greater omentum and along the transverse colon, lying very close to the abdominal wall and filling the entire peritoneal cavity with multiple septation (Figure 2). The cyst was removed. Its histopathological characteristics were consistent with those of cystic lymphangioma. The cyst was lined by endothelial cells, and its walls contained smooth muscle fibers and lymphoid aggregates. The patient was discharged 3 days after cyst removal and continues to do well.

\subsection{Patient 2}

A 9-year-old girl presented with an incidental finding of a painless mass around the umbilicus of 2 weeks' duration. Her blood profile was normal, as were her serum concentrations of alfa-feto-protein and b-human chorionic gonadotrophins. Abdominal examination revealed a movable solid mass in the mid-abdomen. Plain X-rays showed a calcified mass on the right side of the pelvis, suggestive of a right ovarian teratomatous mass (Figure 3). CT showed a cystic mass with areas of fat density and containing calcified foci in the midabdomen (Figure 4). She was diagnosed with teratoma of the right ovary.

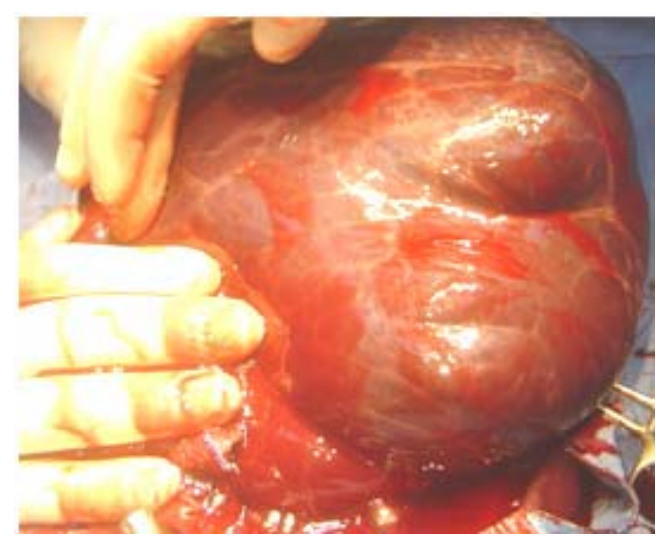

Figure 2. Huge omental cyst about $15 \times 9 \mathrm{~cm}$ filled with blood-stained fluid along the transverse colon with multiple septations.

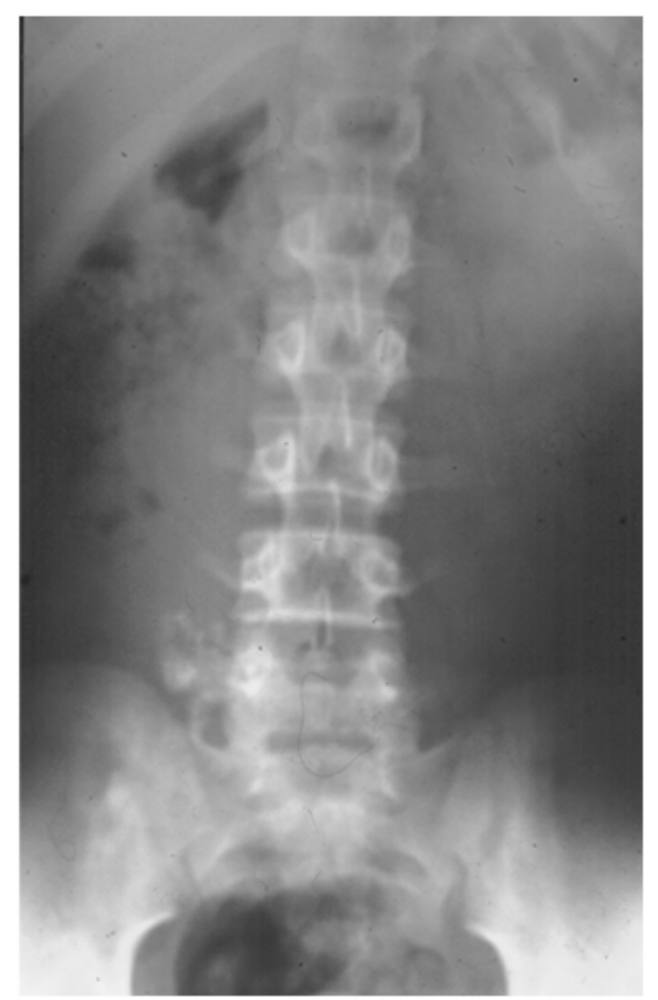

Figure 3. Plain X-ray of the abdomen of patient 2, showing a calcified mass on the right side of the pelvis. 


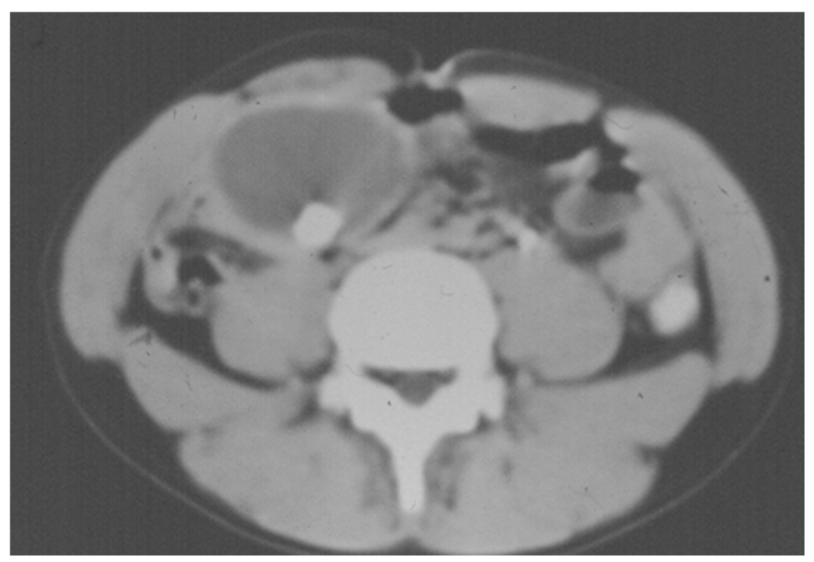

Figure 4. CT abdomen of the lesion.

Laparotomy revealed a $6 \times 5 \times 4 \mathrm{~cm}$ sized mass within the greater omentum, but no right ovary. The mass was excised. Pathological examination revealed findings typical of a cystic teratoma containing hair, fat and foci of calcification. Normal ovarian tissues were also detected. The patient was discharged 3 days after cyst removal and continues to do well.

\section{DISCUSSION}

Intraabdominal cystic lymphatic malformations (retroperitoneal, mesenteric and omental cysts) are rare "tumors" of the abdomen, with an average incidence of approximately one per 105,000 hospital admissions [1-3]. Omental cysts were first described in 1852 [4], and have been since found to be less common than other abdominal cysts [1].

The true etiology of omental cysts has not been established. They are believed to arise from continued proliferation of ectopic lymphatic structures that have no apparent communications with the normal lymphatic system [5-10].

These cysts vary in size from $1.0 \mathrm{~cm}$ to filling the entire abdominal cavity. Omental cysts occur more frequently in childhood, with nearly $70 \%$ diagnosed before age 30 years $[1,9,10]$.

The majority of omental cysts are discovered incidentally. Most of the symptoms from cysts appear to be related to complications, including torsion, hemorrhage [11], infection, and compression of neighboring organs [12-14].

Benign cystic teratoma of the omentum is an extremely rare tumor, with only 28 cases previously reported [14-16]. Several mechanisms may explain the presence of a teratoma in the omentum [15,17-22]. According to one mechanism, a teratoma detaches from the ovary and implants into the omentum due to various mechanical causes, including torsion of an ovarian teratoma with apparent omental implantation [18,19], up- ward displacement of an ovarian teratoma by massive enlargement of the uterus [15] and separation of the ovarian teratoma from the ovary by multiple adhesions [20]. Alternatively, the teratoma may arise from a supernumerary ovary within the omentum $[21,22]$.

Usually, omental teratoma cysts produce no specific symptoms. Their diagnosis can be confirmed only at surgery [23].

The two cases of omental cysts described here are of great interest as they represent very rare clinical and radiographic features.

The first, a 2-year-old girl, presented mainly due to pallor. Hemorrhagic ascites was detected on ultrasound and computer scan. Although few omental cysts have been misdiagnosed as ascites [24-29], none have presented with massive hemorrhagic ascites.

Specific CT features that can differentiate large omental cysts from ascites were not evident in our patient, including separation of bowel loops; absence of fluid from locations in which free moving ascitic fluid usually collects, such as the perihepatic spaces and culde-sac; and focal septation [27].

Our second patient, a 9-year-old girl with a teratomatous omental cyst, is the youngest patient with such a cyst to be described in the literature. The surgical and pathological findings in this patient suggest that this teratomatous omental cyst probably arose as a result of torsion and separation of a right ovarian teratoma with implantation into the greater omentum.

\section{CONCLUSION}

In conclusion, omental cysts are considered to be a rare entity that needs to be taken into consideration. However, they have anticipatable course and favorable outcomes if managed properly.

\section{REFERENCES}

[1] Walker, A.R. and Putnam, T.C. (1973) Omental, mesenteric, and retroperitoneal cysts: A clinical study of 33 new cases. Annals of Surgery, 178, 13-19. http://dx.doi.org/10.1097/00000658-197307000-00003

[2] Bodai, B.I., Jung, W., Marr, C., Smith, P. and Palder, S. (1983) Omnetal cyst: Case report and review of the literature. Contemporary Surgery, 22, 83-86.

[3] Philip, R. (1974) Caropreso: Mesenteric cysts: A review. Archives of Surgery, 108, 242-246. http://dx.doi.org/10.1001/archsurg.1974.01350260094024

[4] Gairdner, W.T. (1851) A remarkable cyst in the omentum. Transactions of the Pathological Society of London, 3, 185-191.

[5] Ford, J.R. (1960) Mesenteric cysts. Review of the literature with report of an 10 unusual case. American Journal of Surgery, 99, 878-884.

http://dx.doi.org/10.1016/0002-9610(60)90478-5 
[6] Beahrs, O.H., Judd Jr, E.S. and Dockerty, M.B. (1950) Chylous cysts of the abdomen. Surgical Clinics of North America, 30, 1081-1096.

[7] Chirathivat, S. and Shermeta, D. (1979) Recurrent retroperitoneal mesenteric cyst. A case report and review. Gastrointestinal Radiology, 4, 191-193. http://dx.doi.org/10.1007/BF01887522

[8] Takiff, H., Calabria, R., Yin, L. and Stabile, B.E. (1985) Mesenteric cysts and intra-abdominal cystic lymphangiomas. Archives of Surgery, 120, 1266-1269. http://dx.doi.org/10.1001/archsurg.1985.01390350048010

[9] Egozi, E.I. and Ricketts, R.R. (1997) Mesenteric and omental cysts in children. American Surgeon, 63, 287290.

[10] Ricketts, R.R. (1998) Mesenteric and omental cysts. In: Pediatric Surgery, 5th Edition, 1269-1275.

[11] Hardin, W.J., Elliott, R.L., Wesson, R.L. and Lowicki, E.M. (1967) Hemorrhagic mesenteric cyst simulating an acute abdomen. American Surgeon, 33, 733-736.

[12] Fish, J.C., Fair, W.R. and Canby, J.P. (1965) Intestinal obstruction in the newborn: An unusual case due tomesenteric cyst. Archives of Surgery, 90, 317-320. http://dx.doi.org/10.1001/archsurg.1965.01320080141029

[13] Brown, R.B. and Shaul, J.F. (1950) Mesenteric cyst complicated by intestinal obstruction: Report of a case. United States Armed Forces Medical Journal, 1, 437-442.

[14] Christensen, J.A., Fuller, J.W., Hallock, J.A., et al. (1975) Mesenteric cysts: A cause. 12. of small bowel obstruction in children. American Surgeon, 41, 352-354.

[15] Moon, W.J., Kim, Y.S., Rhim, H.C., Koh, B.H. and Cho, O.K. (1997) Coexistent cystic teratoma of the omentum and ovary: Report of two cases. Abdominal Imaging, 22, 516-518. http://dx.doi.org/10.1007/s002619900252

[16] Yoshida, A., Murabayashi, N., Shiozaki, T., Okugawa, T. and Tabata, T. (2005) Case of mature cystic teratoma of the greater omentum misdiagnosed as ovarian cyst. Journal of Obstetrics and Gynaecology Research, 31, 399403. http://dx.doi.org/10.1111/j.1447-0756.2005.00309.x

[17] Ralls, P.W., Hartman, B., White, W., et al. (1987) Computed tomography of benign cystic teratoma of the omentum. Journal of Computer Assisted Tomography, 11, 548549. http://dx.doi.org/10.1097/00004728-198705000-00039
[18] Kearney, M.S. (1983) Synchronous benign teratomas of the greater omentum and ovary. Case report. British Journal of Obstetrics and Gynaecology, 90, 676-679. http://dx.doi.org/10.1111/j.1471-0528.1983.tb09290.x

[19] Compton, A.A., Tandon, A. and Fleming, W.P. (1985) Coexistent benign teratomas of the omentum and ovary: A case report. Journal of Reproductive Medicine, 30, 209210.

[20] Ekbladh, L.E. and Fihburne, J.I. (1973) Parasitized dermoid cyst of the omentum. Obstetrics \& Gynecology, 42, 458-460.

[21] Hogan, M.L., Barber, D.D. and Kaufman, R.H. (1967) Dermoid cyst in supernumerary ovary of the greater omentum. Obstetrics \& Gynecology, 129, 405.

[22] Besser, M.J. and Posey, D.M. (1992) Cystic teratoma in a supernumerary ovary of the greater omentum: A case report. Journal of Reproductive Medicine, 37, 189-193.

[23] Fernando, H., Rajan, D., Duvuru, S. and Kanthiah, R. (2006) Omental demoid cyst: Case report and review of the literature. The Internet Journal of Surgery, 7, 13.

[24] Perriello Jr, V.A. and Flemma, R.J. (1969) Lymphangiomatous omental cyst in infancy masquerading as ascites. Journal of Pediatric Surgery, 4, 227-230. http://dx.doi.org/10.1016/0022-3468(69)90396-0

[25] Klin, B., Lotan, G., Efrati, Y. and Vinograd, I. (1997) Giant omental cyst in children presenting as pseudoascites. Surgical Laparoscopy, Endoscopy, 7, 291-293. http://dx.doi.org/10.1097/00019509-199708000-00006

[26] Prema, M. and Rao, K.L.N. (2005) Giant omental cyst masquerading as hemorrhagic ascites. Indian Pediatrics, 42, 395-396.

[27] Lugo-Olivieri, C.H. and Taylor, G.A. (1993) CT differentiation of large abdominal lymphangioma from ascites. Pediatric Radiology, 23, 129-130. http://dx.doi.org/10.1007/BF02012405

[28] Narchi, H. (2000) Omental cyst presenting as pseudoascites. Archives of Pediatrics and Adolescent Medicine, 154, 957-958. http://dx.doi.org/10.1001/archpedi.154.9.957

[29] Gyves-Ray, K., Hernandez, R.J. and Hillemeier, A.C. (1990) Pseudoascites: Unusual presentation of omental cyst. Pediatric Radiology, 20, 560-561. http://dx.doi.org/10.1007/BF02011393 